\title{
Sigma Phase in the Molybdenum-Ruthenium System
}

\author{
by D. S. Bloom
}

$\mathbf{R}$ ECENTLY a report has been published on an investigation of the Mo-Ru system by $\mathrm{E}$. Raub. ${ }^{1}$ In this report it is stated that below approximately $1200^{\circ} \mathrm{C}$ the system consists of two terminal solidsolution phases and the intervening two-phase field; at $1200^{\circ} \mathrm{C}$ and above, an intermetallic compound labeled $\mathrm{Mo}_{5} \mathrm{Ru}_{8}$ makes an appearance.

Along with some other little known systems in which it was considered possible for a $\sigma$ phase to form, the Mo-Ru system had been under investigation in this laboratory. Since molybdenum and ruthenium have very high melting points and also since ruthenium is expensive, the investigation was confined to X-ray diffraction by sintered powder compacts. The compositions which were studied were (in atomic percentages): $75 \mathrm{Mo-25} \mathrm{Ru,} 67 \mathrm{Mo}-33 \mathrm{Ru}$, $50 \mathrm{Mo}-50 \mathrm{Ru}$, and $25 \mathrm{Mo}-75 \mathrm{Ru}$. All compacts were made from the pure powders, and no chemical analyses were attempted. Each compact weighed about $5 \mathrm{~g}$. All annealing was done in evacuated Vycor capsules, and even though the capsules completely collapsed at $1250^{\circ} \mathrm{C}$, they still admitted no air.

The results of this investigation in general corroborate the work of Raub. Up to $1150^{\circ} \mathrm{C}$ the two terminal solutions and the intervening two-phase field were found, and at $1200^{\circ} \mathrm{C}$ and above an intermetallic compound was found. However, the composition limits of the compound were estimated to lie close to 70 atomic pct Mo rather than 62.5 atomic pct Mo as Raub had reported. At least the X-ray diffraction results indicated that the $\mathbf{7 5}$ atomic pct Mo specimen consisted of the molybdenum solid solution plus the compound, while the 67 atomic pct Mo specimen consisted of the ruthenium solid solution plus the compound and the equiatomic composition contained only very little of the compound.

The most interesting observation, however, was that the diffraction pattern of the compound was similar to that of the well known $\sigma$ phases, except that unusually large lattice constants were indicated. The $d$-values, or interplanar spacings, of the diffraction lines (as produced by filtered copper $\mathrm{K} \alpha$ radiation) of the compound are given in Table I, as determined from specimens annealed at $1250^{\circ} \mathrm{C}$ for $9 \mathrm{hr}$ and then quenched in water. Also shown are the lines of the Mn-Mo $\sigma$ phase as given by Decker, Waterstrat, and Kasper, ${ }^{2}$ the lines of the Fe-Mo $\sigma$ as given by Goldschmidt, ${ }^{3}$ and the lines of the Mo-Ru phase multiplied by constants in order to make comparison with the Mn-Mo and Fe-Mo patterns easier. These results indicate that the compound in the Mo$\mathrm{Ru}$ system is apparently isomorphous with the other $\sigma$ compounds.

The rather large lattice constants of the Mo-Ru $\sigma$ phase are acceptable in view of the comparatively large size of the constituent atoms.

The data in Table I for the Mo-Ru compound check quite well with those given by Raub, not shown here, though there are some discrepancies between the

D. S. BLOOM is associated with Michelson Laboratory, United States Ordnance Test Station, Inyokern China Lake, Calif.

TN 262E. Manuscript, Nov. 29, 1954.
Table I. Comparison of Diffraction Patterns of Mn-Mo, Mo-Ru, Fe-Mo $\sigma$ Phases

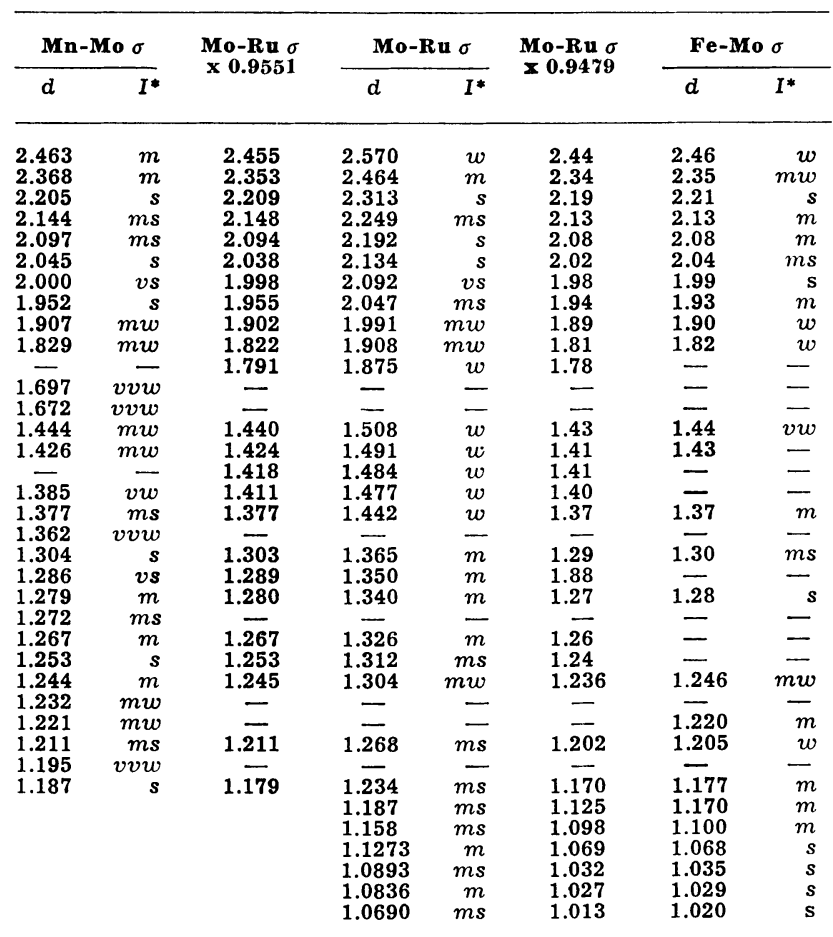

* Standard abbreviations for weak, $w$; medium, $m$; strong, $s$ and very, $v$.

two sets of data in the estimated intensities of a few lines.

Although very little is known at present about this $\sigma$ phase, there are some things which may be pointed out, mainly in comparison with other better known $\sigma$ phases. Even though molybdenum and ruthenium are in the same columns in the Table of Elements as chromium and iron, respectively, the Mo-Ru $\sigma$ phase contains much more molybdenum than ruthenium, while the $\mathrm{Cr}-\mathrm{Fe} \sigma$ phase centers around or very nearly around the equiatomic composition; furthermore, the Mo-Ru $\sigma$ is stable only above approximately $1200^{\circ} \mathrm{C}$, but the $\mathrm{Cr}-\mathrm{Fe} \sigma$ is stable only below about $825^{\circ} \mathrm{C}$. With respect to its being unstable below $1200^{\circ} \mathrm{C}$, the Mo-Ru $\sigma$ is similar to the other binary molybdenum $\sigma$ phases in the Co-Mo and Fe-Mo systems. Similar to the latter two systems, the Mo-Ru $\sigma$ apparently exists over a rather narrow composition range, whereas the $\mathrm{Cr}-\mathrm{Fe} \sigma$ at lower temperatures is stable over a much wider composition range. The Mo-Ru $\sigma$ thus is closer to the other molybdenum $\sigma$ phases than to the $\mathrm{Cr}-\mathrm{Fe}$ $\sigma$ phase. The most striking feature of the Mo-Ru $\sigma$ phase, however, is the absence of any of the transition elements of the First Long Period.

\footnotetext{
1 Ernst Raub: Die hegierungen der Platinmetalle mit Molybdan. Ztsch. für Metallkunde. (1954) 45, No. 1, p. 23 . 2 B. F. Decker, R. M. Waterstrat, and J. S. Kasper: Formation
Sigma Phase in the Mn-Mo System. Trans. AIME (1953) 197, p. 1476: JouRnal OF METALS (November 1953). (1949) 2 , p. 343 .
} 